\title{
UNUSUAL PRESENTATION OF EXTRAPULMONARY TUBERCULOSIS: A CASE REPORT ON MAMMARY TUBERCULOSIS
}

\author{
Munira Khan, $M B C h B, M M e d S c i$ \\ Kogieleum Naidoo, $M B C h B$, Dip HIV Man \\ Centre for the AIDS Programme of Research in South Africa (CAPRISA), University of KwaZulu-Natal, Durban
}

This case study highlights an unusual manifestation of extrapulmonary tuberculosis (TB) in a person living with HIV, namely mammary TB. Clinicians practising in settings where HIV and TB are endemic need to be aware of the clinical presentation, diagnosis and management of mammary TB.

The incidence of extrapulmonary (EP) tuberculosis (TB) is increased in patients with advanced HIV infection. ${ }^{1,2}$ Mammary TB is a rare manifestation of EPTB, and this report describes a case of TB mastitis and TB-associated immune reconstitution syndrome (IRIS) with advanced HIV infection.

\section{CASE REPORT}

A 34-year-old woman presented with a 2-month history of loss of weight, non-productive cough and painful swelling of the right breast. There was no past history of TB, and the patient did not know her HIV status. Clinical examination revealed a unilateral $10 \times 8 \mathrm{~cm}$ mass in the upper outer quadrant of the breast, with no lymph node involvement. A fine-needle aspirate (FNA) was performed and the mass was then incised, drained and dressed. Acid-fast bacilli (AFB) were isolated from the FNA using an auramine stain, and the mycobacterial growth indicator tube culture was positive at 3 weeks. The Mycobacterium tuberculosis (MTB) strain isolated was sensitive to all anti-TB drugs. In addition, concurrent pulmonary tuberculosis (PTB) was diagnosed through a positive sputum AFB smear and compatible changes on the chest radiograph (CXR). The CXR also showed no communication between the lung and chest wall. The intensive phase (IP) of TB treatment, consisting of rifampicin, isoniazid, pyrazinamide and ethambutol, was commenced. An uneventful clinical course followed on TB treatment, and the breast mass resolved completely. The patient accepted counselling and testing for HIV on diagnosis of PTB and was found to be HIV infected.

Sputum smear reversion occurred 2 months after TB diagnosis. The patient was commenced on antiretroviral therapy (ART) after 3 months of TB treatment. A oncedaily regimen of didanosine, efavirenz and lamivudine was chosen because of its substantial potency and tolerability with TB treatment. The patient presented 2 weeks after initiation of ART with a 4-day history of a painful sternal mass. Clinical findings included newonset generalised lymphadenopathy, a $3 \mathrm{~cm}$ tender erythematous sternal mass with overlying desquamation, a $5 \mathrm{~cm}$ firm non-tender right breast mass recurring in the previous site, and two $10 \mathrm{~cm}$ soft, non-tender mobile masses, one over the left scapula and the other centrally over the spinal column. A full blood count demonstrated bicytopenia, neutropenia and normochromic anaemia with abnormally low folate levels. The patient's CD4 count was 163 cells/ $\mu$ land her viral load 932553 copies/ $\mathrm{ml}(\log 5.97)$.

Staphylococcus aureus was isolated from a pus swab of the sternal lesion and treated with a course of flucloxacillin. A Ziehl-Neelsen stain of an FNA of the breast mass isolated AFB but was culture negative. Cytology demonstrated thick inflammatory/necrotic debris with numerous epithelial granulomas, and no ductal cells.

The patient completed 7 months of TB treatment and uninterrupted ART. Eighteen months after ART initiation, her CD4 count was 480 cells/ $\mu$ l with an undetectable viral load. The sternal and breast masses had resolved completely. However, the patient refused excision biopsy for histologically confirmed lipomas on the posterior chest wall.

\section{DISCUSSION}

In the pre-AIDS era, incidence rates of TB mastitis were $0.1 \%$ and $3 \%$ of all breast lesions in developed and developing countries, respectively. ${ }^{3}$ However, reports of TB of the breast are becoming more common with the advancing HIV epidemic, especially over the past decade (Table I).

In immunocompromised patients in particular, haematogenous spread of MTB from a primary focus can result in mammary TB. The primary site of TB in this report was the lung parenchyma. TB of the breast most commonly presents as a lump in the central or upper outer quadrant of the breast, ${ }^{18}$ as in this case. Diagnosis is based on multiple factors including clinical history, examination, histological features, and in some cases response to empiric TB treatment. FNA of the breastlesion remains the single most important diagnostic method. ${ }^{14}$ Histopathological examination reveals suppuration and 


\section{TABLE I. SUMMARY OF LITERATURE REVIEW OF TB MASTITIS CASES}

\begin{tabular}{|c|c|c|c|c|}
\hline \multirow[b]{2}{*}{ Author, year } & \multirow[b]{2}{*}{ No. of cases } & \multicolumn{3}{|c|}{ Isolation of MTB } \\
\hline & & Breast only & Co-morbid PTB & $\begin{array}{l}\text { Pattern of drug- } \\
\text { resistant TB, site }\end{array}$ \\
\hline Kalaç et al. ${ }^{4}$ & 5 & 4 & 1 & RI resistance, lung \\
\hline Tewari and Shukla ${ }^{5}$ & 30 & 30 & - & - \\
\hline Khanna et al. ${ }^{6}$ & 52 & 52 & - & - \\
\hline Green and Ormerod ${ }^{7}$ & 10 & 5 & 5 & IE resistance, breast \\
\hline Morino et al. ${ }^{8}$ & 2 & 1 & 1 & - \\
\hline Sakr et al. ${ }^{9}$ & 10 & 10 & - & - \\
\hline Ahmed and Sultan ${ }^{10}$ & 10 & 2 & 8 & - \\
\hline Sriram et al..$^{11^{*}}$ & 1 & 1 & - & - \\
\hline Fadaei-Araghi et al. ${ }^{12}$ & 8 & 1 & - & - \\
\hline Kumar and Sharma ${ }^{13}$ & 1 & 1 & - & RIS resistance, breast \\
\hline Kakkar et al. ${ }^{14}$ & 164 & 164 & - & - \\
\hline O'Reilly et al. ${ }^{15}$ & 1 & 1 & - & - \\
\hline Al-Marri et al. ${ }^{16}$ & 13 & 13 & - & - \\
\hline Harris et al. ${ }^{17}$ & 38 & 33 & 5 & - \\
\hline
\end{tabular}

a degree of necrotising inflammation that is uncommon in profoundly immunocompromised patients. ${ }^{19}$

The development of the breast mass after initiation of ART may be related to the unmasking of TB-associated IRIS. It is unusual for MTB-associated IRIS to present as a breast mass; commonly fever, lymphadenopathy or worsening pulmonary symptoms characterise MTB IRIS.

This case highlights the need for a high index of suspicion of EPTB presenting in unusual sites particularly against a background of high TB and HIV prevalence. It also demonstrates the clinical diagnostic and management dilemmas faced by clinicians in this setting.

The US President's Emergency Plan for AIDS Relief (PEPfAR) funded the care of patients in the CAT Programme. The Global Fund to fight AIDS, Tuberculosis and Malaria funded the drugs used in the CAT Programme. The sponsors of the study had no role in study design, writing or the decision to submit the material for publication.

Posts held and contribution to article: Munira Khan, research clinician: concept, drafting and writing of paper; Kogieleum Naidoo, head of treatment programme: assisted with writing and editing of paper.

Ethics approval: The University of KwaZulu-Natal Biomedical Research Ethics Committee (reference number E 248/05) approved the retrospective chart review.
Conflict of interest: The authors declare that there are no conflicts of interest.

Conference presentation: Part of this case report was accepted for presentation at the 40th Union World Conference on Lung Health, 3 - 7 December 2009, Cancun, Mexico.

\section{REFERENCES}

1. Jones BE, Young SM, Antoniskis D, Davidson PT, Kramer F, Barnes PF. Relationship of the manifestations of tuberculosis to CD4 cell counts in patients with human immunodeficiency virus infection. Am Rev Respir Dis 1993:148:1292-1297.

2. Barnes PF, Bloch AB, Davidson PT, Snider DE Jr. Tuberculosis in patients with human immunodeficiency virus infection. N Engl J Med 1991;324:1644- 1650.

3. Hamit HF, Ragsdale TH. Mammary tuberculosis. J R Soc Med 1982;75:764.

4. Kalaç N, Ozkan B, Bayiz H, Dursun AB, Demirağ F. Breast tuberculosis. Breast 2002;11:346-349

5. Tewari M, Shukla HS. Breast tuberculosis: diagnosis, clinical features and management. Indian J Med Res 2005;122:103-110.

6. Khanna R, Prasanna GV, Gupta P, Kumar M, Khanna S, Khanna AK. Mammary tuberculosis: report on 52 cases. Postgrad Med J 2002;78:422-424.

7. Green RM, Ormerod L. Mammary tuberculosis: rare but still present in the United Kingdom. Int J Tuberc Lung Dis 2000;4:788-790.

8. Morino GF, Rizzardi G, Gobbi F, Baldan M. Breast tuberculosis mimicking other diseases. Trop Doct 2007:37:177-178.

9. Sakr AA, Fawzy RK, Fadaly G, Baky MA. Mammographic and sonographic features of tuberculous mastitis. Eur J Radiol 2004;51:54-60.

10. Ahmed R, Sultan F. Granulomatous mastitis: a review of 14 cases. J Ayub Med Coll Abbottabad 2006;18:52-54.

11. Sriram K, Moffatt D, Stapledon R. Tuberculosis infection of the breast mistaken for granulomatous mastitis: a case report. Cases J 2008;1:273

12. Fadaei-Araghi M, Geranpayeh L, Irani S, Matloob R, Kuraki S. Breast tuberculosis: report of eight cases. Arch Iran Med 2008;11:463-465.

13. Kumar P, Sharma N. Primary MDR-TB of the breast. Indian J Chest Dis Allied Sci 2003 Jan-Mar;45(1):63-65.

14. Kakkar S, Kapila K, Singh MK, Verma K. Tuberculosis of the breast. A cytomorphologic study. Acta Cytol 2000;44:292- 296.

15. O'Reilly M, Patel KR, Cummins R. Tuberculosis of the breast presenting as carcinoma. Mil Med 2000;165:800-802.

16. Al-Marri MR, Almosleh A, Almoslmani Y. Primary tuberculosis of the breast in Qatar: ten year experience and review of the literature. Eur J Surg 2000;166:687-690.

17. Harris SH, Khan MA, Khan R, Haque F, Syed A, Ansari MM. Mammary tuberculosis: analysis of thirty-eight patients. Aust N Z J Surg 2006:76:234-237.

18. Gupta R, Gupta AS, Duggal N. Tubercular mastitis, Int Surg 1982:67:422-424.

19. Cabie A, Abel S, Brebion A, Desbois N, Sobesky G. Mycobacterium lymphadenitis after initiation of highly active antiretroviral therapy. Eur J Clin Microbiol Infect Dis 1998;17:812- 813 